\title{
THE ANEMIA OF INFECTION. XIII. STUDIES ON EXPERI- MENTALLY PRODUCED ACUTE HYPOFERREMIA IN DOGS AND THE RELATIONSHIP OF THE ADRENAL CORTEX TO HYPOFERREMIA ${ }^{1}$
}

\author{
By G. E. CARTWRIGHT, L. D. HAMILTON, ${ }^{2}$ C. J. GUBLER, N. M. FELLOWS, \\ HELEN ASHENBRUCKER, AND M. M. WINTROBE
}

\begin{abstract}
(From the Departments of Medicine and Surgery, College of Medicine, University of Utah, Salt Lake City)
\end{abstract}

(Submitted for publication, August 17, 1950; accepted, November 6, 1950)

Hypoferremia is one of the most consistent features of the anemia associated with chronic infections in man (1). By what mechanism infection produces hypoferremia is not known. It has been reported previously that in dogs an acute, transient, hypoferremia of pronounced degree develops following the experimental production of an infected (staphylococcus) or a sterile (turpentine) intramuscular abscess (2). Since sterile abscesses produce hypoferremia, it is evident that bacteria and their products are not essential for the reaction. It has, furthermore, been possible to demonstrate that in dogs the intravenous injection of colloidal thorium dioxide is associated with a pronounced hyperferremia and that following the injection of thorium the hypoferremia-producing effect of turpentine does not develop (3). It would appear, therefore, that in infection the reticulo-endothelial system is stimulated to store iron.

By the use of intravenously injected radioactive iron, it has been shown that the utilization of iron for hemoglobin synthesis is impaired in the presence of infection $(4,5)$. Furthermore, the administration of extremely large amounts of iron intravenously in man fails to relieve the anemia and the hypoferremia persists (6). There is a reduced uptake of iron by the heme of the red blood corpuscles and the iron is diverted mainly to the liver and spleen (7). This would seem to indicate that whatever the mechanism whereby the low level of iron in the plasma is produced, it is extremely powerful and cannot be easily overcome.

The purpose of the experiments reported here

1 Aided by a grant from the United States Public Health Service and the Upjohn Company, Kalamazoo, Michigan.

2 Postdoctorate Research Fellow of the United States Public Health Service 1949-50. was to study further the mechanism by which inflammation produces hypoferremia in dogs.

\section{METHODS}

In these studies approximately $200 \mathrm{male}$ and female mongrel dogs weighing between 10 and $15 \mathrm{~kg}$. were used. Of these 65 were adrenalectomized. The animals were fed Purina Dog Chow and allowed water ad libitum except during the experimental procedures, at which time they were fasted.

Adrenalectomies were performed in one stage. The dogs were anesthetized with 5 per cent nembutal intravenously, and the adrenal glands were exposed and removed through the transabdominal approach. Sterile precautions were used throughout the procedure.

At the beginning of the operation the dogs were given an intramuscular injection of $5 \mathrm{ml}$. of aqueous or $0.5 \mathrm{ml}$. of lipo-adrenal cortical extract, and a similar dose was given on its completion. Desoxycorticosterone acetate was found to be of little supportive value at this stage and dogs supported with this steroid during the operative procedure invariably failed to survive adrenalectomy. During the operation the animals received an intravenous infusion of $250-500 \mathrm{ml}$. of 5 per cent dextrose in normal saline. Dogs of medium size survived adrenalectomy best. For the first three days following the operation, the dogs were given 0.5 to $1 \mathrm{ml}$. of lipo-adrenal or $5 \mathrm{ml}$. of aqueous adrenal cortical extract intramuscularly daily. After this they were given $0.5 \mathrm{ml}$. of lipo-adrenal cortical extract every two or three days. No extract was given for at least 48 hours before the start of an experimental procedure. At one period during these experiments, the supply of adrenal cortical extract was limited and the dogs were maintained postoperatively on $1 \mathrm{mg}$. desoxycorticosterone acetate intramuscularly every day.

For the first week postoperatively the dogs were fed a diet of rolled oats to which sodium chloride, sucrose and milk were added. Thereafter, they were given a Purina Dog Chow diet with a 0.9 per cent solution of sodium chloride to drink.

All glassware used for the collection of blood samples and for the determination of plasma iron was carefully cleansed with acid and washed three times with water double distilled in an all glass distillation apparatus. Ve- 
nous blood samples were drawn into all glass syringes and placed in $15 \mathrm{ml}$. centrifuge tubes to which two drops of 20 per cent potassium oxalate had been added previously. The plasma was then separated by centrifugation and the iron estimation made by a modification (8) of the method of Barkan and Walker (9), the Beckman spectrophotometer being used.

To estimate the errors introduced by differences in venipuncture samples, the handling of the blood and the iron estimations themselves, four consecutive samples were drawn in four separate venipunctures from each of five dogs. The time which elapsed from the taking of the first sample and the last did not exceed five minutes. Dogs with a wide range of plasma iron levels were chosen for this experiment to see if the level affected the degree of variability within a single dog. Table I gives the results obtained. The standard error of a single determination was calculated for these results

$$
\left(\text { S.D. }=\sqrt{\frac{\Sigma\left(\mathrm{X}-\overline{\mathrm{X}}_{\mathrm{s}}\right)^{2}}{\mathrm{n}-1}}\right)
$$

and was found to be $\pm 3.7 \mu \mathrm{g}$. per cent.

In the earlier experiments, samples were taken for iron estimation immediately before an experimental procedure and at intervals throughout the 24 hour period. Additional samples were then taken at 48,72 and 96 hours. In subsequent experiments samples for iron determinations were restricted to one immediately before an experimental procedure and one at six, eight and 24 hours following this. Portions of these samples, collected in a mixture of ammonium and potassium oxalate, were used for the determination of the volume of packed red blood cells and for cell counts. Total leukocyte counts, differential blood cell counts and absolute eosinophil counts were made immediately before an experimental procedure and at two, four and six hours following it. These were carried out in the hope that they might serve as indices of adrenocortical activity (10-12). Total white and differential blood cell counts were carried out by routine methods. The differential cell determinations were made on duplicate cover slip preparations. $200-500$ cells were examined for each count. Absolute eosinophil counts were made by the phloxine propylene glycol method (13). Duplicate counts were made in 16 squares of a Fuchs' Rosenthal counting chamber of $0.2 \mathrm{~mm}$. depth.

\section{TABLE I}

Variations in the plasma iron in four consecutive samples from five dogs

Values are in $\mu \mathrm{g}$. per cent

\begin{tabular}{c|c|c|c|c|c}
\hline \hline & \multicolumn{5}{|c}{ Dog number } \\
\cline { 2 - 6 } Sample & 1 & 2 & 3 & 4 & 5 \\
\hline 1 & 74 & 56 & 59 & 292 & 112 \\
2 & 71 & 59 & 56 & 290 & 107 \\
3 & 78 & 55 & 64 & 290 & 112 \\
4 & 73 & 50 & 68 & 290 & 102 \\
\hline
\end{tabular}

TABLE II

Variations in the total white blood cell counts per c.mm. in four consecutive samples from six dogs

\begin{tabular}{c|c|c|c|c|c|c}
\hline \hline & \multicolumn{6}{|c}{ Dog number } \\
Sample & 1 & 2 & 3 & 4 & 5 & 6 \\
\hline 1 & 13,400 & 9,600 & 8,350 & 6,800 & 7,900 & 23,100 \\
2 & 14,000 & 9,600 & 9,000 & 6,700 & 6,250 & 23,750 \\
3 & 13,900 & 8,800 & 9,250 & 8,300 & 8,200 & 23,300 \\
4 & 14,250 & - & 7,450 & 8,400 & 8,750 & 25,300 \\
\hline
\end{tabular}

To determine the variations which might be attributed to technical factors in making the absolute white cell and eosinophil counts, four consecutive samples were drawn into double oxalate with four separate venipunctures from each of six dogs. The time which elapsed from the taking of the first sample and the final one did not exceed five minutes. The results obtained are given in Tables II and III.

It is obviously not possible to compare absolute values for white blood cell counts of one animal with those of another. However, if the changes are expressed in proportion to the original count, it is possible to compare these percentage changes from animal to animal. The standard error of a single determination of the total white blood cell count has been calculated from the data in Table II and found to be \pm 9.1 per cent.

The standard error of a single determination of the absolute eosinophil count, calculated from the results in Table III gives a value \pm 10.3 per cent.

In the differential cell count the white blood cells were divided into four types: polymorphonuclear cells, cosinophils, lymphocytes and monocytes. The absolute number of each type of cell was determined by multiplying the per cent of each cell in the differential count by the total number of white blood cells. The absolute numbers of each type of cell subsequent to an experimental procedure were then expressed as a percentage of the initial level. The observed changes in the monocyte counts appeared to have no definite trend and these have been excluded from the results.

All data have been treated statistically where possible. The standard error of the mean has been calculated and is given with mean values. The $t$ test has been used to estimate the significance of differences between groups.

TABLE III

Variations in the absolute eosinophil counts per c.mm. in four consecutive samples from six dogs

\begin{tabular}{l|c|c|c|c|c|c}
\hline \hline & \multicolumn{6}{|c}{ Dog number } \\
\hline Sample & 1 & 2 & 3 & 4 & 5 & 6 \\
\cline { 2 - 6 } & 294 & 169 & 56 & 406 & 506 & 500 \\
1 & 284 & 120 & 44 & 447 & 494 & 547 \\
2 & 288 & 138 & 50 & 383 & 444 & 512 \\
3 & 278 & - & 38 & 413 & 525 & 531 \\
\hline
\end{tabular}


RESULTS

\section{Studies in Intact Dogs}

The effect of taking blood samples and of a single injection of normal saline on the plasma iron. To evaluate the part played by the taking of blood samples on variations of the plasma iron, and also to measure the variations with the time of day, five dogs were bled at regular intervals during the day and three dogs were given $5.0 \mathrm{ml}$. saline intramuscularly and also bled after the initial sample had been drawn (Figures 1 and 2). There was no difference in the variations observed in those dogs which received no treatment and in those which received the injection of saline. Both groups may therefore be considered as belonging to the same population. In seven dogs there was some lowering of the plasma iron level between six and eight hours after the initial sample, the mean per cent decrease for the group being $24 \pm 6$. The iron level of one dog rose during the day. The levels of all eight dogs returned to their initial value at the end of 24 hours. It is interesting to note (Figure 1) that the per cent decrease in the plasma iron of four dogs was approximately 50 and that in the other four the range was from 0 to -17 , the latter values being for the most part within the variations to be expected with the experimental methods used. This point and the correlation between these changes and those observed

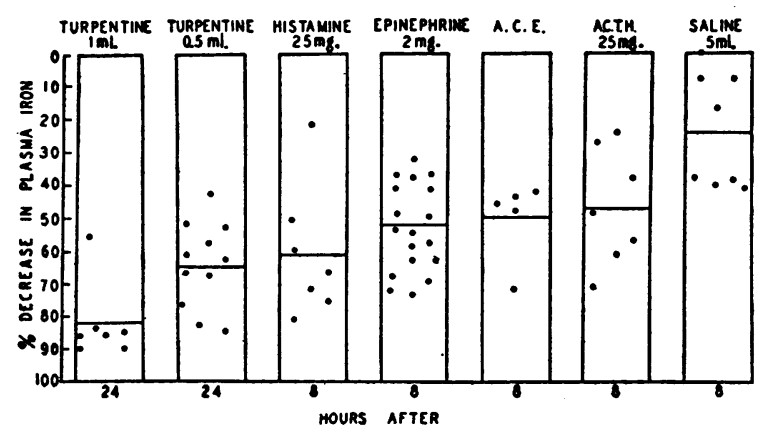

Fig. 1. The Maximal Hypoferremia-Producing EfFECT IN THE DOG OF THE INTRAMUSCULAR INJECTION OF 1 ML. AND 0.5 ML. OF TURPENTINe; 25 Mg. OF Histamine; 2 mg. of Epinephrine; Adrenal Cortical Extract; 25 MG. OF ACTH; AND OF MILd "Stress" as Represented by the Injection of 5 ML. Saline

Each point represents the maximal decrease in the plasma iron of a single dog.
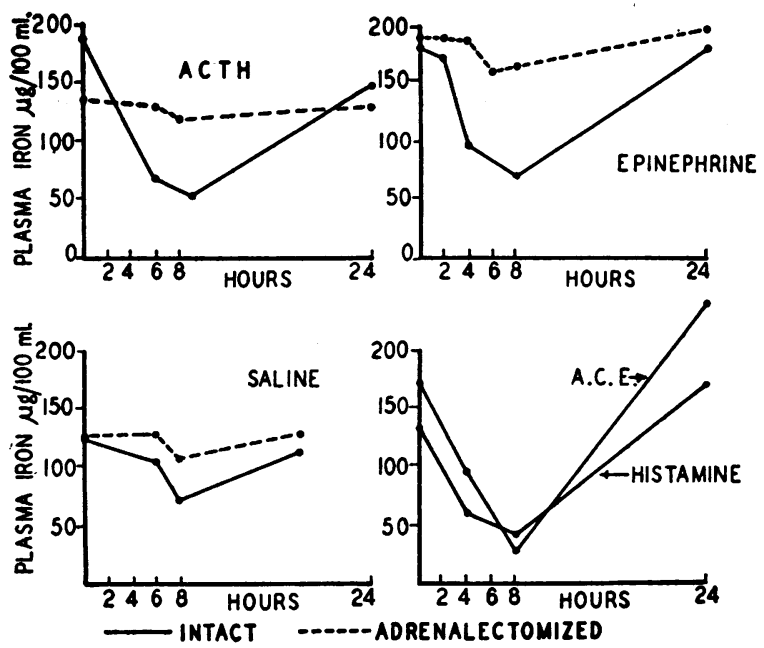

Fig. 2. Representative Examples of the Changes in the Plasma Iron Produced by the Intramuscular INJECTION OF 25 Mg. OF ACTH; 2 MG. OF EPINEPHRINE; 5.0 Ml. of 0.9 Per Cent Saline, in Intact (Continuous LiNe) and Adrenalectomized (DotTed Line) Dogs, AND BY THE INTRAMUSCULAR INJECTION OF 25 MG. OF Histamine and the IntrapertToneal Injection of 120 ML. of Aqueous Adrenal Cortical Extract in Intact Dogs

in the cellular elements of the blood will be dealt with in greater detail in the discussion.

The effect of turpentine on the plasma iron. In earlier studies it was shown that the intramuscular injection of 5 or $10 \mathrm{ml}$. of turpentine (rectified oil of turpentine, Rexall, USP) was followed by characteristic changes in the plasma iron $(2,3)$. The level of iron was significantly lowered in 24 hours and reached its lowest values within 24 to 48 hours, the mean per cent decrease being $78 \pm 3$. This hypoferremic phase was followed by a hyperferremic phase of brief duration, after which the plasma iron returned to normal. Similar results have been obtained in this investigation following the injection of $1.0 \mathrm{ml}$. (in seven dogs) and $0.5 \mathrm{ml}$. (in 11 dogs) of turpentine. After 24 hours these amounts produced mean decreases in the plasma iron level of $82 \pm 5$ and $65 \pm 4$ per cent, respectively (Table IV). The percentage decrease following the injection of $1.0 \mathrm{ml}$. and of $0.5 \mathrm{ml}$. of turpentine for each individual dog is plotted in Figure 1.

The effect of histamine on the plasma iron. A single intramuscular injection of $25 \mathrm{mg}$. of histamine in aqueous solution was associated with 
TABLE IV

The hypoferremic effect of a variety of agents in intact and adrenalectomized dogs

\begin{tabular}{|c|c|c|c|c|c|c|c|c|c|c|c|c|c|c|c|}
\hline \multirow{2}{*}{$\begin{array}{c}\text { Substance } \\
\text { injected }\end{array}$} & \multirow{2}{*}{ Group } & \multirow{2}{*}{$\begin{array}{c}\text { No. of } \\
\text { dogs }\end{array}$} & \multicolumn{3}{|c|}{$\begin{array}{l}\text { Initial P.I. } \\
\text { Mg. per cent }\end{array}$} & \multicolumn{3}{|c|}{$\begin{array}{l}\text { Lowest subsequent } \\
\text { P.I. } \mu \text { g. per cent }\end{array}$} & \multicolumn{3}{|c|}{$\begin{array}{l}\text { Decrease in P.I. } \\
\text { MQ. per cent }\end{array}$} & \multicolumn{3}{|c|}{$\begin{array}{l}\text { Per cent decrease } \\
\text { in P.I. }\end{array}$} & \multirow{2}{*}{\begin{tabular}{|l}
$\begin{array}{c}\text { Time } \\
\text { after } \\
\text { injection }\end{array}$ \\
Hours
\end{tabular}} \\
\hline & & & Mean & S.E. & Range & Mean & S.E. & Range & Mean & S.E. & Range & Mean & S.E. & Range & \\
\hline Histamine & Intact & 7 & 149 & \pm 17 & $102-234$ & 55 & \pm 8 & $20-83$ & 94 & \pm 18 & $23-178$ & 61 & \pm 8 & $22-81$ & 8 \\
\hline $\begin{array}{l}\text { Adrenal } \\
\text { cortical } \\
\text { extract }\end{array}$ & Intact & 5 & 145 & \pm 17 & 103-195 & 72 & \pm 11 & $48-113$ & 75 & \pm 14 & $47-125$ & 50 & \pm 5 & $42-72$ & 8 \\
\hline $\begin{array}{l}\text { Turpentine } \\
5.0 \mathrm{ml} \text {. }\end{array}$ & Intact & 10 & 174 & \pm 11 & $110-229$ & 38 & \pm 2 & $22-45$ & 136 & \pm 12 & $65-194$ & 78 & \pm 3 & $59-89$ & 24 \\
\hline $\begin{array}{l}\text { Turpentine } \\
1.0 \mathrm{ml} \text {. }\end{array}$ & Intact & 7 & 169 & \pm 21 & $64-253$ & 25 & \pm 1 & $20-30$ & 145 & \pm 22 & $36-228$ & 82 & \pm 5 & $56-90$ & 24 \\
\hline $\begin{array}{l}\text { Turpentine } \\
0.5 \mathrm{ml} \text {. }\end{array}$ & Intact & 11 & 130 & \pm 14 & $63-216$ & 43 & \pm 5 & $23-91$ & 86 & \pm 12 & $27-174$ & 65 & \pm 4 & $43-85$ & 24 \\
\hline $\begin{array}{l}\text { Turpentine } \\
0.5 \mathrm{ml} \text {. } \\
\text { Epinephrine } \\
2.0 \mathrm{mg} \text {. } \\
\text { ACTH } \\
25 \mathrm{mg} \text {. } \\
\text { Saline } \\
5.0 \mathrm{ml} \text {. }\end{array}$ & $\begin{array}{l}\text { Intact } \\
\text { Adect. } \\
\text { Intact } \\
\text { Adect. } \\
\text { Intact } \\
\text { Adect. } \\
\text { Intact } \\
\text { Adect. }\end{array}$ & $\begin{array}{r}11 \\
5 \\
18 \\
9 \\
7 \\
6 \\
8 \\
11\end{array}$ & $\begin{array}{r}130 \\
114 \\
136 \\
113 \\
160 \\
107 \\
127 \\
68\end{array}$ & $\begin{array}{l} \pm 14 \\
\pm 20 \\
\pm 9 \\
\pm 15 \\
\pm 23 \\
\pm 13 \\
\pm 14 \\
\pm 8\end{array}$ & $\begin{array}{l}63-216 \\
66-154 \\
53-190 \\
38-191 \\
84-274 \\
63-145 \\
79-195 \\
41-124\end{array}$ & $\begin{array}{r}89 \\
91 \\
61 \\
85 \\
79 \\
99 \\
101 \\
70\end{array}$ & $\begin{array}{l} \pm 14 \\
\pm 20 \\
\pm 5 \\
\pm 14 \\
\pm 8 \\
\pm 11 \\
\pm 13 \\
\pm 17\end{array}$ & $\begin{array}{l}36-177 \\
46-147 \\
33-119 \\
28-160 \\
55-117 \\
51-122 \\
60-157 \\
48-115\end{array}$ & $\begin{array}{r}41 \\
24 \\
75 \\
29 \\
82 \\
11 \\
32 \\
4\end{array}$ & $\begin{array}{l} \pm 10 \\
\pm 4 \\
\pm 8 \\
\pm 7 \\
\pm 20 \\
\pm 4 \\
\pm 11 \\
\pm 2\end{array}$ & $\mid \begin{array}{c}0-93 \\
12-35 \\
20-126 \\
0-58 \\
23-157 \\
0-26 \\
0-76 \\
0-15\end{array}$ & $\begin{array}{r}32 \\
22 \\
53 \\
26 \\
47 \\
10 \\
24 \\
5\end{array}$ & $\begin{array}{l} \pm 7 \\
\pm 5 \\
\pm 3 \\
\pm 6 \\
\pm 7 \\
\pm 3 \\
\pm 6 \\
\pm 3\end{array}$ & $\mid \begin{array}{r}0-72 \\
5-30 \\
32-74 \\
0-47 \\
24-71 \\
0-19 \\
0-41 \\
0-24\end{array}$ & $\begin{array}{l}8 \\
8 \\
8 \\
8 \\
8 \\
8 \\
8 \\
8\end{array}$ \\
\hline
\end{tabular}

changes in the plasma iron similar to those which followed the injection of turpentine. They differed from those which followed turpentine in that the maximum hypoferremia occurred within six to eight hours instead of 24 to 48 ; at 24 hours after histamine injection the iron level returned to its previous level or was in the brief hyperferremic phase. The mean per cent decrease in the plasma iron of seven dogs at six to eight hours after histamine injection was $61 \pm 8$ (Table IV). Figure 2 is a representative example of the change in the plasma iron level following the injection of histamine while the decreases for each individual dog are given in Figure 1.

Repeated intramuscular injections of $20 \mathrm{mg}$. of histamine in aqueous solution were given to two

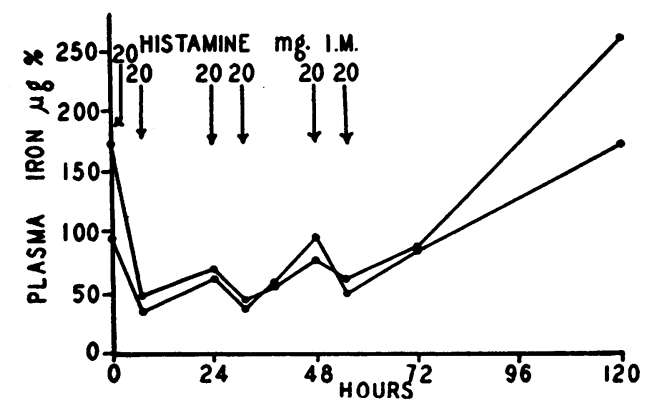

Fig. 3. The Effects of the Repeated Intramuscular Injection of 20 mg. of Histamine on the Plasma Iron of Two Dogs dogs over three days. Both dogs received an injection of histamine at 9:00 a.m. and at 4:00 p.m. on each of three days. The first injection of histamine was followed by a marked decrease in the plasma iron level of the two dogs. Twenty-four hours after the initial injection of histamine the level showed a tendency to revert to its previous value. The level of iron at 48 hours, with the one exception, remained lower than the value prior to the first injection of histamine. At 65 hours after the last injection the levels of iron in both dogs were considerably greater than the initial values and reverted to the initial levels some 24 to 48 hours later. These results are shown in Figure 3. During the period of the repeated injections of histamine the volume of packed red cells of both dogs remained constant.

The effect of epinephrine on the plasma iron. A single intramuscular injection of $2.0 \mathrm{ml}$. of $1: 1,000$ epinephrine in aqueous solution to $10 \mathrm{dogs}$ and of $2.0 \mathrm{ml}$. of $1: 500$ epinephrine in oil to eight dogs was followed by a hypoferremia similar to that resulting from histamine (Figure 2). Maximal hypoferremia occurred between six and eight hours after the injection. The plasma iron after 24 hours returned to its pre-injection level or higher. There was no difference in the time, and no correlation between the extent of the alteration of the plasma iron produced by the two doses and 


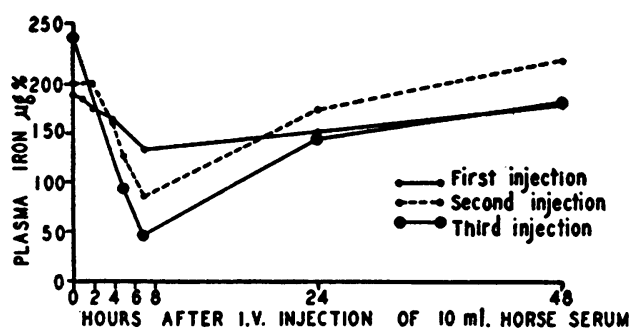

Fig. 4. The Changes in the Level of Plasma Iron of a Dog following the Production of Anaphylactic Shock by the Intravenous Injection of Horse Serum

the preparations of epinephrine used. The mean per cent decrease in the plasma iron level was $53 \pm$ 3 (Table IV). The decrease for each dog is plotted in Figure 1.

The effect of anaphylactic shock on the plasma iron. The single intravenous injection of $10 \mathrm{ml}$. of horse serum to a dog, which two weeks previously had received $10 \mathrm{ml}$. of horse serum intravenously, was followed by a 20 per cent decrease in the plasma iron at seven hours. The plasma iron level returned to its pre-injection level within 48 hours. Within a few minutes after the injection of the horse serum the dog showed considerable reaction including urination and defecation. Fourteen days later a second intravenous injection of $10 \mathrm{ml}$. of horse serum was given to the same dog. This was followed by a severe reaction, and seven hours later the plasma iron decreased 58 per cent below its initial level. At 24 to 48 hours the concentration of plasma iron had returned toward the pre-injection level. Seven weeks later the same dog was given a third intravenous injection of $10 \mathrm{ml}$. horse serum. This time the dog showed only a slight reaction but seven hours following the injection the level of iron had decreased 80 per cent, to return to its pre-injection level at 48 hours. The effects of the three injections of horse serum are shown in Figure 4.

The effect of fracture of the femur on the plasma iron. Two dogs were anesthetized with 5.0 per cent sodium pentobarbital. It had been found in nine dogs that sodium pentobarbital anesthesia had an effect on the plasma iron identical with that of mild stress or the intramuscular injection of saline, the mean per cent decrease at six to eight hours being $22 \pm 10$. Following fracture of the femur under anesthesia, the plasma iron level de- creased 39 and 33 per cent, respectively, in the two dogs at seven hours but maximal hypoferremia occurred at 24 hours, at which time the decrease was 75 and 46 per cent, respectively. The level of plasma iron then rose again at 48 hours and at 72 hours was approaching its pre-fracture level (Figure 5). Thus in their temporal relationships the alterations in the plasma iron level produced by fracture resemble those produced by turpentine, rather than those produced by histamine, epinephrine or mild stress.

The effect of miscellaneous "stresses" on the plasma iron. The single intramuscular injection of $5 \mathrm{ml}$. of formaldehyde in one dog was followed in seven hours by a 46 per cent decrease in the plasma iron level. Four dogs were kept for eight hours at $-20^{\circ} \mathrm{C}$. The stress of cold had no consistent effect on the level of plasma iron.

The effect of adrenal cortical extract on the plasma iron. Five dogs were given single injections of adrenal cortical extract. Two received 30 $\mathrm{ml}$. of lipo-adrenal and one $60 \mathrm{ml}$. of aqueous adrenal cortical extract intramuscularly. The remaining two received $40 \mathrm{ml}$. and $120 \mathrm{ml}$. of aqueous adrenal cortical extract intraperitoneally, the alcohol having been removed previously. The variations in the doses and routes of administration used did not produce discernible differences in the variations in the plasma iron level. As with histamine and epinephrine maximum hypoferremia occurred between six and eight hours after the injection, the mean per cent decrease for the five dogs being $50 \pm 5$ (Table IV). The level of iron returned to its previous value or higher at 24

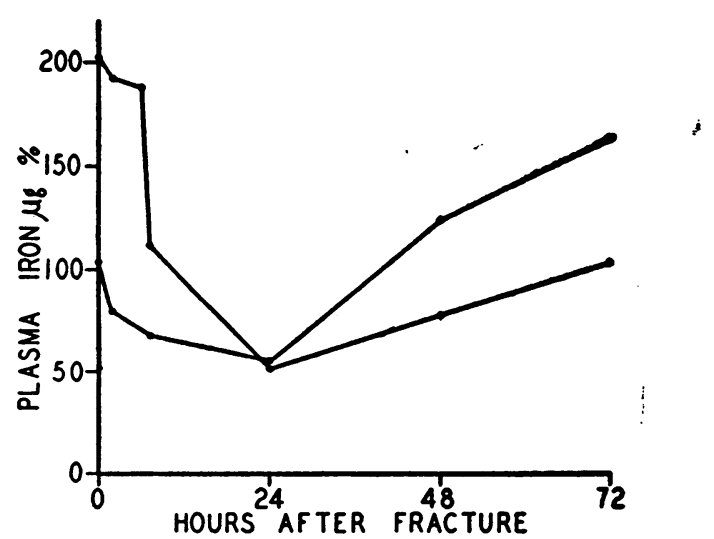

Fig. 5. The Effects of Fracture of the Femur on the Level of Plasma Iron in Two Dogs 
hours. A typical response is shown in Figure 2 and the individual decreases for the five dogs are plotted in Figure 1.

The effect of adrenocorticotrophic hormone $(A C T H)$ on the plasma iron. A single injection of ACTH was given to five dogs. Of these, two received the injection intramuscularly and three intravenously. The dose for all five was equivalent to $25 \mathrm{mg}$. of Armour's standard (LA-1-A) dissolved in $5 \mathrm{ml}$. normal saline. An additional two dogs were given a dose equivalent to $60 \mathrm{mg}$. of Armour's standard (LA-1-A) given intravenously in five divided doses at 30 minute intervals for two hours. The changes in the plasma iron level were similar for all seven dogs and they will be considered as a group. There was a maximal drop in the plasma iron of all dogs between six and eight hours after the last injection of ACTH, the mean per cent decrease being $47 \pm 7$ (Figure 1). This was followed, as with histamine, epinephrine and adrenal cortical extract, by a return of the iron to its pre-injection level or to a slightly higher level after 24 hours (Figure 2).

The effect of Dibenamine ( $N, N$-Dibenzyl- $\beta$ Chloroethyl-Amine-Hydrochloride) on the plasma iron. Three dogs were given a single intravenous injection of $20 \mathrm{mg}$. per $\mathrm{kg}$. of body weight of $\mathrm{Di}$ benamine in $30 \mathrm{ml}$. of 0.9 per cent solution of sodium chloride. The animals showed signs of cen-

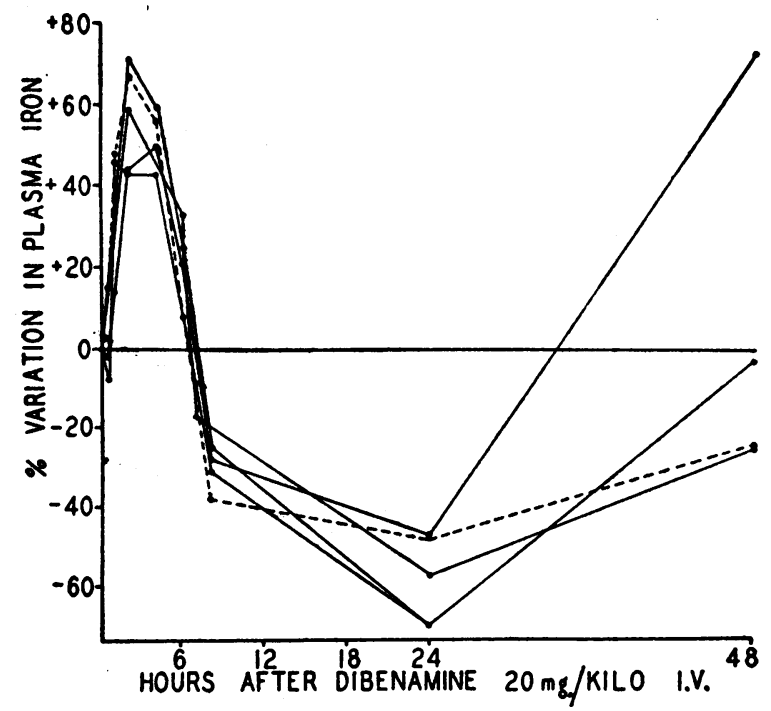

Fig. 6. The Changes in the Plasma Iron of Five Dogs following the INTRAvenous Administration or 20 MG. PER KG. OF Dibenamine

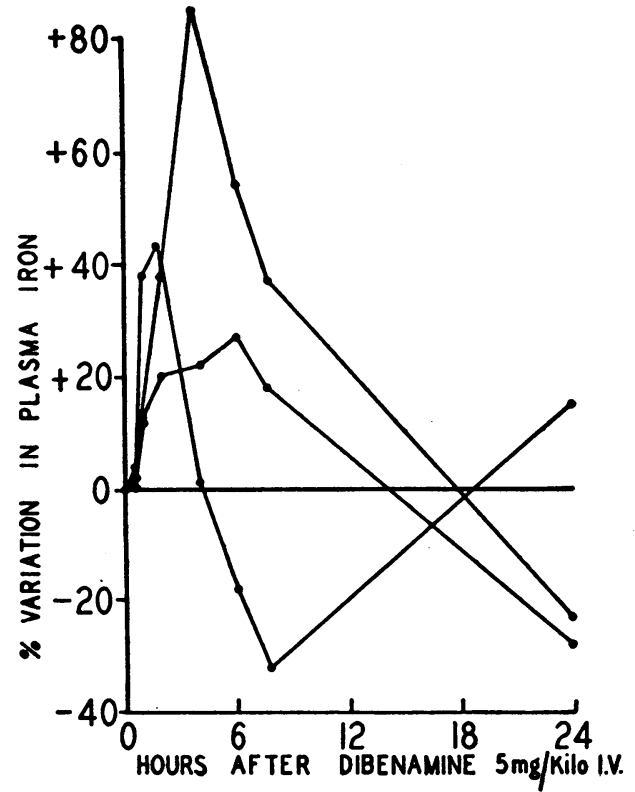

Fig. 7. The Changes in the Plasma Iron of Three Dogs fOllowing the INTRAVENous Administration of 5 MG. PER KG. OF Dibenamine

tral excitation with tremors and vomiting within 30 minutes. Another three dogs received the same dose of Dibenamine in a $200 \mathrm{ml}$. infusion of 0.9 per cent solution of sodium chloride over 10 minutes and showed some excitation but this had no untoward results. The effects of the injection of $\mathrm{Di}$ benamine on the level of plasma iron were identical for both groups. Within one hour following the injection, the level of the plasma iron began to rise and a maximum increase was reached at approximately two hours after the injection of the drug, the mean per cent increase over the initial iron level being $59 \pm 4$. At six hours following the injection the level of iron had fallen towards the preinjection level and at eight hours it was below this level, with a mean per cent decrease of $30 \pm 3$. At 24 hours the hypoferremia was maximal, the mean per cent decrease from the initial iron level being $60 \pm 5$; this was followed by a return towards the control level at 48 hours. These results are shown in Figure 6.

Following the intravenous administration of 5 mg. per kg. of body weight of Dibenamine in 200 $\mathrm{ml}$. of 0.9 per cent solution of sodium chloride to three dogs there were no demonstrable signs of central excitation. The plasma iron level rose in all three dogs within the first two hours following 


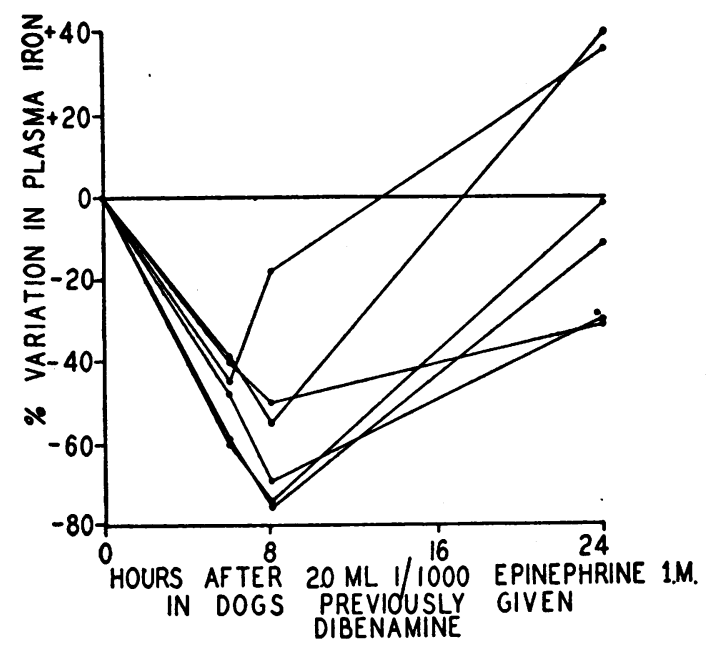

Fig. 8. The Changes in the Plasma Iron followING THE INTRAMUSCULAR INJEction OF 2 Mg. OF EPInephrine in Six Dogs Previously Given Drbenamine

the injection but the hypoferremic phase which usually took place between six and eight hours after stress occurred only in one dog, the other two showing moderate hypoferremia at the 24 hour period (Figure 7). The differences in the variations in the plasma iron level produced by the two doses of Dibenamine will be correlated with the changes noted in the cells. The significance of this correlation is considered in the discussion.

The effect of epinephrine following the administration of Dibenamine on the plasma iron level. A single intramuscular injection of $2 \mathrm{mg}$. of epinephrine in aqueous solution was given to six dogs. Three of these had previously received 20 $\mathrm{mg}$. per $\mathrm{kg}$. of body weight of Dibenamine, while the other three received $5 \mathrm{mg}$. per $\mathrm{kg}$. of body weight of Dibenamine. The epinephrine was given to one dog from each dosage group at 24,48 and 72 hours after the administration of Dibenamine. In all six dogs the injection of epinephrine was followed by a decrease in the plasma iron level which was maximal between six and eight hours after the injections. At 24 hours the iron level showed a tendency to revert to its pre-injection value (Figure 8 ). The mean per cent decrease in the plasma iron below the initial levels was $61 \pm 5$. This is very similar to the decrease following the injection of epinephrine in otherwise untreated intact dogs. Thus Dibenamine failed to block the hypoferremic effect of epinephrine.

\section{Studies in Adrenalectomized Dogs}

The effect of adrenalectomy on the plasma iron level. A minimum of one week was allowed to elapse following adrenalectomy before a dog was used in an experiment. The mean initial plasma iron levels were all lower in the adrenalectomized group than in the corresponding intact group (Table IV). However, in only one group was the decrease significant and this was in the mildly stressed group $(\mathrm{P}=<.001)$. The dogs in this group were maintained largely on desoxycorticosterone acetate and not on adrenal cortical extract.

This tendency to a lowering of the plasma iron level following adrenalectomy would have been more marked if several adrenalectomized dogs, whose pre-injection plasma iron levels were very low, had not been excluded from the results in order that the initial iron levels of intact and adrenalectomized groups might be more comparable.

The effect of mild stress on the plasma iron. Samples were taken from three adrenalectomized dogs at regular intervals throughout the day and eight adrenalectomized dogs were given $5 \mathrm{ml}$. of 0.9 per cent sodium chloride solution intramuscularly. The effect on the plasma iron level of all dogs was identical and, in contrast to the changes noted in intact dogs, the plasma iron levels showed no significant change (Figure 9). The maximum mean per cent decrease noted was $5 \pm 3$ which is

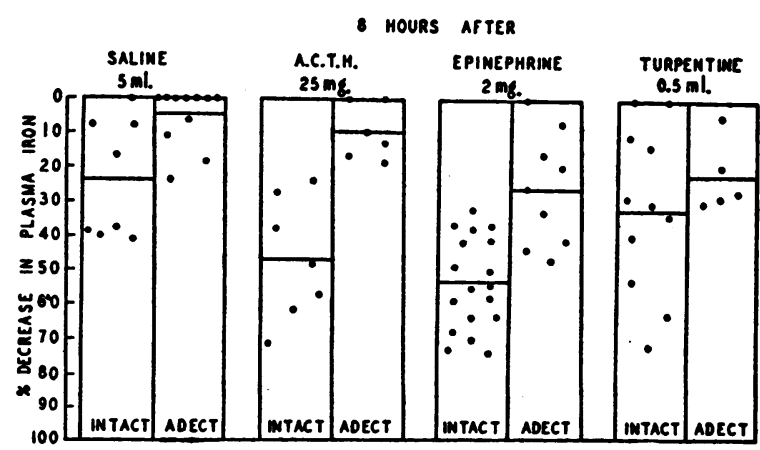

Fig. 9. The Maximal Hypoterremia-Producing EfFEct of Mild Stress (Saline), of the Intrayuscular INJECTION OF 25 MG. OF ACTH, 2 MG. OF EPINEPHRINE AND 0.5 M. OF TURpentine In INTACT aNd AdrenalecTOMIZED Dogs

Each point represents the maximal decrease in the plasma iron of an individual dog. 
within the experimental error of the methods used. There was a significant difference between the intact and adrenalectomized dogs in the decrease in plasma iron in $\mu \mathrm{g}$. per cent $(\mathrm{P}=<.001)$ and in the percentage decrease in the plasma iron following mild stress $(P=<.01)$. Thus adrenalectomy abolished the hypoferremic effect of mild stress.

The effect of turpentine on the plasma iron. The intramuscular injection of $1 \mathrm{ml}$. of turpentine in two adrenalectomized dogs resulted in their death within six hours. The dose was therefore reduced to $0.5 \mathrm{ml}$. Five dogs survived this dose until eight hours after the injection but only two survived for 24 hours. Of these two survivors, the iron level of one showed a 48 per cent decrease from its pre-injection value, and the level of the other showed no change. The latter is the only dog in our series in which the intramuscular injection of turpentine did not produce hypoferremia (Figure 10). An additional adrenalectomized dog was given a single injection of $0.5 \mathrm{ml}$. of turpentine, this animal being supported throughout the 24 hour period with three intramuscular injections of $5 \mathrm{ml}$. of aqueous adrenal cortical extract. We had previously found, in two intact dogs, that the single intramuscular injection of 25 $\mathrm{ml}$. of aqueous adrenal cortical extract was not sufficient to cause a lowering of the plasma iron. In this dog the injection of turpentine was followed by a fall in the plasma iron level at 24 hours, comparable with the mean per cent decrease obtained in the intact dogs. These results are shown in Figure 10.

It can be seen from the scatter diagram in Figure 9 that there was no significant difference between the level of the plasma iron of intact and adrenalectomized dogs at eight hours following the injection of turpentine. It should be noted that maximum hypoferremia with turpentine does not occur until 24 hours after its injection.

The effect of adrenocorticotrophic hormone on the plasma iron. A single intramuscular injection of $25 \mathrm{mg}$. ACTH in $5 \mathrm{ml}$. of 0.9 per cent solution of sodium chloride to six dogs was not followed by any significant change in the plasma iron level (Figure 9). The maximum mean per cent decrease was $10 \pm 3$ which again was within the experimental error of the methods used. There was a significant difference between the intact and adrenalectomized dogs in the decrease in the plasma iron expressed in $\mu \mathrm{g}$. per cent $(P=.01)$ and in the percentage decrease in the plasma iron following $\mathrm{ACTH}(\mathrm{P}=<.001)$. Thus ACTH had no hypoferremic effect in the absence of the adrenal glands.

The effect of epinephrine on the plasma iron. A single injection of $2 \mathrm{mg}$. of epinephrine in aqueous solution was given intramuscularly to nine adrenalectomized dogs. Following the injection of epinephrine there was a decrease in the level of plasma iron which was maximal between six and eight hours and returned to its pre-injection level within 24 hours. The mean per cent

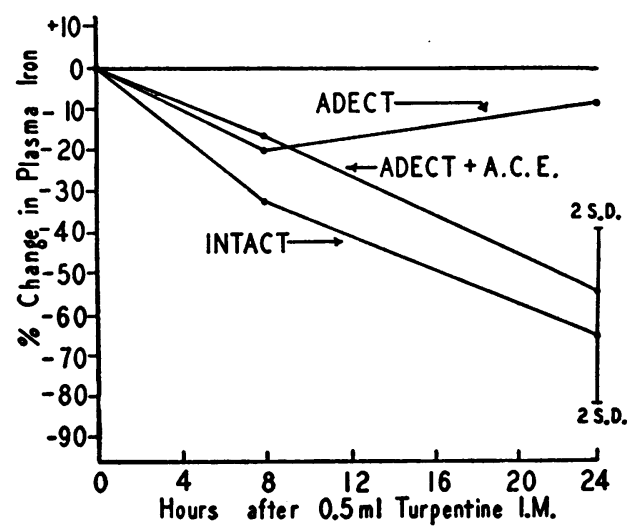

Fig. 10. The Mean Per Cent Change in the Level of the Plasma Iron of 11 Intact Dogs following the INTRAMUSCULAR INJECTION OF 0.5 ML. OF TURPENTINE, with a Line Indicating the 95 Per Cent Range of Maximal Hypoferremia after 24 Hours

The changes in the plasma iron of an adrenalectomized dog which survived the intramuscular injection of $0.5 \mathrm{ml}$. of turpentine and of another adrenalectomized dog which was supported with $15 \mathrm{ml}$. of adrenal cortical extract during this period are also shown.

decrease in plasma iron for the group was $26 \pm 6$ (Table IV). This decrease was significantly different from that obtained in the intact dog following epinephrine $(\mathrm{P}=<.001)$. This decrease was also significantly different from the effect of mild stress and saline in the adrenalectomized dogs $(\mathrm{P}=<.01)$. Thus epinephrine produced a significant hypoferremia in the absence of the adrenal cortex, but this was significantly less than that which was obtained in the intact dog. This is shown in Figure 9.

The effect of adrenocorticotrophic hormone, colloidal thorium dioxide and adrenalectomy on the rate of the removal of colloidal saccharated oxide 


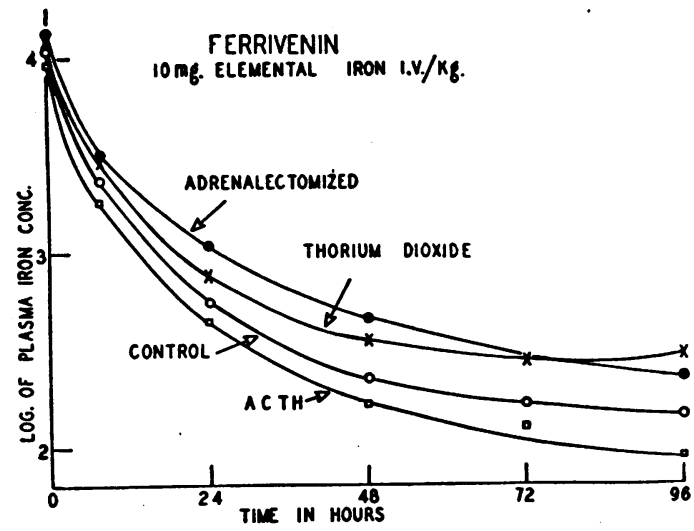

Fig. 11. The Rate of Disappearance of IntraveNOUSLy AdMINISTERED SaCcharated OXIDE OF IRON From the Plasma of Four Groups of Dogs; Intact Untreated (Control), Intact Previously Injected with Colloidal Thorium Dioxide, Intact and Given ACTH, and Adrenalectomized

of iron from the plasma. An intravenous injection of saccharated oxide of iron (SKF brand) equivalent to $10 \mathrm{mg}$. of elemental iron per $\mathrm{kg}$. of body weight was given to four groups of dogs. These consisted of an intact untreated group of four dogs ; an intact group of four dogs given $10 \mathrm{mg}$. ACTH before the injection of the iron and at $6,12,24,30$ and 36 hours following its administration; an adrenalectomized group of three dogs; and an intact group of four dogs which had received intravenous injections of $2 \mathrm{ml}$. per $\mathrm{kg}$. of body weight of colloidal thorium dioxide (Thorotrast, Heyden Company, New York City) for three consecutive days, the iron being given 24 hours after the last injection of the thorium. Blood samples for the estimation of plasma iron were drawn immediately before the injections of the intravenous iron and at 10 minutes, $8,24,48,72$ and 96 hours following it.
TABLE $v$

White blood cell counts per c.mm. in intact and adrenalectomized dogs

\begin{tabular}{|c|c|c|c|c|}
\hline \multirow{2}{*}{ Cells } & \multicolumn{2}{|r|}{ Intact } & \multicolumn{2}{|c|}{ Adrenalectomized } \\
\hline & $\begin{array}{c}\text { No. of } \\
\text { dogs }\end{array}$ & Mean \pm S.D. & $\begin{array}{l}\text { No. of } \\
\text { dogs }\end{array}$ & Mean \pm S.D. \\
\hline $\begin{array}{l}\text { Total } \\
\text { Neutrophils } \\
\text { Lymphocytes }\end{array}$ & $\begin{array}{l}64 \\
59 \\
59\end{array}$ & $\begin{array}{r}12,940 \pm 3,600 \\
9,300 \pm 3,000 \\
2,528 \pm 1,160\end{array}$ & $\begin{array}{l}24 \\
24 \\
24\end{array}$ & $\begin{array}{r}12,800 \pm 3,900 \\
8,000 \pm 2,650 \\
3,100 \pm 1,460\end{array}$ \\
\hline
\end{tabular}

In the four groups of dogs the iron was removed most rapidly from the plasma of the dogs given injections of ACTH and most slowly from the plasma of the adrenalectomized dogs. The rate of disappearance of iron from the plasma of the intact untreated dogs fell between these two groups, and that from the plasma of the dogs previously given thorium dioxide came between the rate of disappearance of iron from the intact untreated controls and the adrenalectomized dogs. These results are shown in Figure 11.

Four days after the administration of the saccharated oxide of iron, the intact dogs previously given thorium dioxide, were given a single intramuscular injection of $25 \mathrm{mg}$. of histamine. The mean per cent decrease in the plasma iron was $16 \pm 10$ which was significantly different from the $61 \pm 8$ per cent decrease obtained following the injection of histamine in intact untreated dogs $(\mathrm{P}=<.01)$.

\section{Studies on the Leukocytes of Intact and Adrenal- ectomized Dogs Before and After the In- jection of Various Substances}

The mean cell counts in intact and adrenalectomized dogs before they were subjected to any experimental procedures are summarized in Table V.

TABLE VI

Maximum per cent changes in the level of the white blood cells following the injection of $a$ variety of agents in intact and adrenalectomized dogs

\begin{tabular}{|c|c|c|c|c|c|c|c|c|c|c|}
\hline \multirow{2}{*}{$\begin{array}{l}\text { Substance } \\
\text { injected }\end{array}$} & \multirow{2}{*}{ Group } & \multirow{2}{*}{$\begin{array}{l}\text { No. of } \\
\text { dogs }\end{array}$} & \multicolumn{2}{|c|}{ WBC. } & \multicolumn{2}{|c|}{ PMN } & \multicolumn{2}{|c|}{ Eosinophils } & \multicolumn{2}{|c|}{ Lymphocytes } \\
\hline & & & Mean \pm S.E. & Range & Mean \pm S.E. & Range & Mean \pm S.E. & Range & Mean \pm S.E. & Range \\
\hline $\begin{array}{l}\text { Turpentine } \\
0.5 \mathrm{ml} \text {. }\end{array}$ & $\begin{array}{l}\text { Intact. } \\
\text { Adect. }\end{array}$ & $\begin{array}{r}10 \\
4\end{array}$ & $\begin{array}{l}+60 \pm 13 \\
+32 \pm 11\end{array}$ & $\begin{array}{l}9-127 \\
3-56\end{array}$ & $\begin{array}{l}+83 \pm 16 \\
+58 \pm 14\end{array}$ & $\begin{array}{l}38-187 \\
17-78\end{array}$ & $\begin{array}{l}-81 \pm 6 \\
-38 \pm 7\end{array}$ & $\begin{array}{l}(-37)-(-100) \\
(-21)-(-51)\end{array}$ & $\begin{array}{l}-42 \pm 6 \\
+15 \pm 26\end{array}$ & $\begin{array}{r}(0)-(-69) \\
(+81)-(-28)\end{array}$ \\
\hline $\begin{array}{l}\text { Epinephrine } \\
2.0 \mathrm{mg} .\end{array}$ & $\begin{array}{l}\text { Intact. } \\
\text { Adect. }\end{array}$ & $\begin{array}{l}5 \\
6\end{array}$ & $\begin{array}{l}+74 \pm 17 \\
+15 \pm 4\end{array}$ & $\begin{array}{c}32-118 \\
0-28\end{array}$ & $\begin{array}{l}+125 \pm 26 \\
+21 \pm 4\end{array}$ & $\begin{array}{c}60-194 \\
6-34\end{array}$ & $\begin{array}{l}-80 \pm 10 \\
+19 \pm 10\end{array}$ & $\left\{\begin{array}{l}-47)-(-100) \\
+97)-(-43)\end{array}\right.$ & $\begin{array}{l}-62 \pm 6 \\
+33 \pm 29\end{array}$ & $\begin{array}{l}(-51)-(-81) \\
(+136)-(-55)\end{array}$ \\
\hline$\underset{25}{\text { ACTH }}$ & $\begin{array}{l}\text { Intact. } \\
\text { Adect. }\end{array}$ & $\begin{array}{r}10 \\
6\end{array}$ & $\begin{array}{l}+58 \pm 9 \\
+35 \pm 15\end{array}$ & $\begin{array}{l}0-104 \\
4-90\end{array}$ & $\begin{array}{ll}+103 & \pm 6 \\
+37 & \pm 15\end{array}$ & $\begin{array}{r}11-193 \\
2-100\end{array}$ & $\begin{array}{l}-84 \pm 6 \\
+50 \pm 23\end{array}$ & $\begin{array}{l}(-37)-(-100) \\
(+134)-(-40)\end{array}$ & $\begin{array}{l}-30 \pm 7 \\
+21 \pm 26\end{array}$ & $\begin{array}{r}(0)-(-63) \\
(+131)-(-48)\end{array}$ \\
\hline Saline $5.0 \mathrm{ml}$ & $\begin{array}{l}\text { Inact. } \\
\text { Adect. }\end{array}$ & $\begin{array}{r}10 \\
6\end{array}$ & $\begin{array}{l}+29 \pm 10 \\
+24 \pm 13\end{array}$ & $\begin{array}{l}0-94 \\
0-75\end{array}$ & $\begin{array}{l}+41 \pm 10 \\
+23 \pm 12\end{array}$ & $\begin{array}{l}5-111 \\
0-79\end{array}$ & $\begin{array}{l}-30 \pm 10 \\
+30 \pm 32\end{array}$ & $\begin{array}{r}(0)-\left(\begin{array}{l}-77) \\
(+140)\end{array}-(-67)\right.\end{array}$ & $\begin{array}{l}-21 \pm 5 \\
+36 \pm 21\end{array}$ & $\begin{array}{l}(-1)-(-46) \\
(+97)-(-27)\end{array}$ \\
\hline
\end{tabular}


The figures for the intact dog are in close agreement with those given by Gardner (14) in her most comprehensive review of the literature on the blood picture in the dog.

There was no difference between the total leukocyte count of intact as compared with adrenalectomized dogs. There was a tendency for the lymphocytes to be increased $(\mathrm{P}=<.2)$ and for the polymorphonuclear cells to be decreased ( $P=$ $<.5$ ) in the adrenalectomized dogs although these differences were not statistically significant.

The maximum percentage changes noted in the leukocytes following the intramuscular injection of turpentine, epinephrine, ACTH and saline in both intact and adrenalectomized dogs are summarized in Table VI.

Following the injection of turpentine, epinephrine and ACTH into intact dogs there was a rise in the total white blood cell and polymorphonuclear cell counts (maximal at six hours following the injection) and a significant decrease in the eosinophils (maximal at six hours) and in the lymphocytes (maximal at four hours). Following the injection of these agents in adrenalectomized dogs there was a tendency for the increases in the white blood cell and polymorphonuclear cell counts to be less than those obtained in the intact animals but these differences were only significant in the epinephrine group. Turpentine was the only agent which produced a significant decrease in eosinophils in the absence of the adrenal cortex. However, this decrease was significantly less than that obtained in intact dogs given turpentine $(\mathrm{P}=<$ $.01)$. In contrast to the intact dogs, the lymphocytes of the adrenalectomized animals showed a tendency to increase rather than decrease following the administration of each of the three agents.

It is interesting to note in greater detail the effects of mild stress on the leukocytes of intact dogs. Of the eight intact dogs on which plasma iron estimations were also made, there were four in which the per cent decrease in iron was significant and four in which it was not. Of the four in which the iron showed a significant decrease, blood cell counts were made on three and the mean increase of the white blood cell and polymorphonuclear cell counts were 51 and 62 per cent. Of the four dogs in which the iron showed no significant change, cell counts were simultaneously taken on three and the mean per cent increase of the white blood cell and polymorphonuclear cell counts were 9 and 24, showing a direct correlation between the change in the level of plasma iron and changes in the level of the cell counts. Similarly, in the three dogs with a decrease in the level of plasma iron, the per cent fall in the eosinophils and lymphocytes averaged 71 and 20, respectively, and in the three dogs which did not show a change the per cent fall was 54 and 9 , respectively.

Two hours following the intravenous injection in three dogs of $20 \mathrm{mg}$. per $\mathrm{kg}$. of body weight of Dibenamine in $200 \mathrm{ml}$. of 0.9 per cent solution of sodium chloride, there was a marked hyperferremia and a mean per cent increase in the total white blood count and polymorphonuclear count of $15 \pm$ 8 and $25 \pm 11$, respectively. Both the eosinophils and lymphocytes showed a decrease at this period of $24 \pm 5$ and $15 \pm 13$ per cent. The total leukocytes and polymorphonuclear cells increased to a maximum eight hours following Dibenamine at which time they showed a mean per cent increase of $65 \pm 20$ and $90 \pm 25$, over their initial counts. The greatest fall in the eosoinophil count was at six hours, when they showed a decrease of $71 \pm 7$ per cent, and in the lymphocytes at four hours, when they had decreased by $42 \pm 8$ per cent. These changes in the cells coincided with the change in the plasma iron level from a hyperferremic to a hypoferremic phase. At 24 hours when the level of iron was still depressed, the total leukocyte and polymorphonuclear counts were still elevated to $53 \pm 19$ and $55 \pm 24$ per cent above their initial levels. The drop in the level of eosinophils had decreased to $35 \pm 13$ per cent and the lymphocytes had returned to their pre-injection level or higher in all three dogs.

Following the intravenous injection in three dogs of $5 \mathrm{mg}$. per $\mathrm{kg}$. of body weight of Dibenamine in $200 \mathrm{ml}$. of 0.9 per cent solution of sodium chloride, the changes noted in the cells were different from those obtained with the large doses. Two hours following the Dibenamine the mean per cent increase of the white blood cell and polymorphonuclear cell counts was $13 \pm 13$ and $32 \pm 32$. These increases were due entirely to increases in the total leukocyte and polymorphonuclear cell count of the one dog which developed a hypoferremia following this dose of Dibenamine. The eosinophils and lymphocytes had decreased at this period by $23 \pm 11$ and $37 \pm 9$ per cent. The in- 
creases in the white blood cell and polymorphonuclear cell counts were maximal at six hours, being $34 \pm 16$ and $30 \pm 11$ per cent. At this period the eosinophils showed a maximal decrease of $41 \pm 11$ per cent. The maximal decrease of the lymphocytes occurred after four hours, at which time they had fallen to $29 \pm 5$ per cent below their initial level. All the changes noted in the cells were less than those obtained with the larger dose of Dibenamine although these differences were not statistically significant, due probably to the small number of dogs used.

The six dogs previously injected with Dibenamine were given a single intramuscular injection of $2 \mathrm{mg}$. of epinephrine. The changes in the white blood cell counts observed were very similar to those obtained in untreated dogs with epinephrine. Thus at six hours after the injection of the epinephrine there was a maximal increase in the total leukocyte count and polymorphonuclear cells of $53 \pm 6$ and $74 \pm 11$ per cent, respectively, and a maximal decrease of the eosinophils of $66 \pm 5$ per cent. The lymphocytes had fallen to their lowest value at four hours, the mean per cent decrease noted being $41 \pm 6$. Thus Dibenamine neither blocked the cellular changes nor the hypoferremia which followed the injection of epinephrine.

\section{DISCUSSION}

From these results it would appear that there is a relation between adrenocortical function and the level of plasma iron. Thus, it has been found that a variety of agents other than turpentine are capable of inducing hypoferremia in the dog. These include histamine, epinephrine, formaldehyde, fracture, anaphylactic shock and the mild stress of taking blood samples. The hypoferremia which followed epinephrine and histamine differed from that which followed turpentine in that maximal hypoferremia occurred in six to eight hours rather than in 24 to 48 hours.

Following the injection of adrenocortical extract and ACTH, hypoferremia developed at the same time as after histamine, epinephrine and anaphylactic shock, and to a similar degree. That the effect of ACTH was mediated through the adrenal cortex was demonstrated by the fact that in adrenalectomized dogs no hypoferremia was produced by the injection of ACTH. Hypoferremia caused by mild stress was also absent in the adrenalectomized dog. The hypoferremic effect of epinephrine was significantly less in adrenalectomized dogs than in intact animals $(\mathrm{P}=<.001)$ but epinephrine still produced a significant fall in plasma iron in the absence of the adrenal cortex $(P=$ $<.01$ ).

Additional evidence of an association between the adrenal cortex and the level of plasma iron was afforded by the experiments on the rate of disappearance from the plasma of intravenously administered saccharated oxide of iron. This' substance was removed most rapidly from the plasma of intact dogs given ACTH, and most slowly from the plasma of adrenalectomized dogs, the rate of disappearance in intact untreated animals falling between these two. The rate of disappearance from dogs previously given thorium dioxide was approximately equal to that of the adrenalectomized dogs. The urinary excretion of iron was not studied in these animals. Such studies are indicated and are now under way in this laboratory.

The correlation found in these studies between the production of lymphopenia with eosinopenia and hypoferremia may be adduced as further evidence of the association of the adrenal cortex with the mechanism of hypoferremia. Thus turpentine, epinephrine, and ACTH produced hypoferremia in intact dogs and they also produced a significant eosinopenia and lymphopenia. Following bleeding or the injection of saline, a significant fall in the eosinophils and lymphocytes only took place in those dogs which developed a hypoferremia. It has been shown by others that Dibenamine, in doses of $25 \mathrm{mg}$. per $\mathrm{kg}$. of body weight, produces a fall in adrenal ascorbic acid concentration (15), and in this study the above dose of Dibenamine produced a hypoferremia which was accompanied by a significant eosinopenia and lymphopenia. Following the administration of $5 \mathrm{mg}$. per $\mathrm{kg}$. of body weight of Dibenamine the one dog which developed hypoferremia at eight hours also showed significant cell changes. In the two dogs in which hypoferremia did not develop at eight hours the cell changes were much less pronounced. Furthermore in dogs pretreated with Dibenamine, epinephrine produced both hypoferremia and eosinopenia and lymphopenia.

In adrenalectomized animals turpentine was the 
only substance which produced a significant mean per cent decrease in the circulating eosinophils, but even when turpentine was injected the decrease in the eosinophils in the adrenalectomized dogs was significantly less than the drop obtained in the intact animals $(\mathrm{P}=<.01)$. In the adrenalectomized dogs following the administration of ACTH the eosinophils showed a tendency to increase. This increase was significantly different from the decrease associated with hypoferremia produced in intact dogs $(\mathrm{P}=<.001)$. The hypoferremia produced by epinephrine in the intact dog was associated with a significant decrease in the circulating eosinophils. In the absence of the adrenal cortex, epinephrine produced a hypoferremia which was significantly less than that obtained in the intact dog and which was not associated with a significant decrease in the eosinophils. This is further evidence that the full hypoferremic effect of epinephrine can only be produced in the presence of the adrenal cortex, but it is also clear that it acts in part through another system.

If from the above evidence we assume that the adrenal cortex is one of the factors concerned in the regulation of the plasma iron level and specifically is concerned in the production of the hypoferremia of stress, the problem arises as to how this influence is mediated. In the previous paper in this series (3), it was demonstrated that the intravenous administration of colloidal thorium dioxide to dogs in amounts of $2 \mathrm{ml}$. per $\mathrm{kg}$. of body weight per day for three consecutive days resulted in a marked hyperferremia and that under these circumstances the hypoferremia produced by the intramuscular injection of turpentine, even in doses as great as $5 \mathrm{ml}$., was almost entirely prevented. In the present investigation it has been shown that the hypoferremia producing effect of histamine is blocked in a similar manner. These findings together with the observation that iron accumulates in organs containing the cells of the reticulo-endothelial system under conditions of chronic stress $(7$, $16,17)$ suggest that it is the reticulo-endothelial system which removes the iron from the plasma.

One possible explanation of the means whereby acute hypoferremia is produced following stress is that the cortical hormones stimulate the reticuloendothelial system to take up the iron from the plasma. In support of this explanation is the observation of Gordon and Katsh (18) that in rats adrenalectomy results in a significant decrease in the uptake of thorium by the spleen while the administration of whole adrenal cortical extract significantly increases the accumulation of thorium in the spleens of adrenalectomized animals.

This explanation is admittedly entirely speculative at the present time. It is possible that $\mathrm{ACTH}$ and cortisone produce hypoferremia through an entirely different mechanism than does turpentine. Indeed, it has been shown in the present study that epinephrine and turpentine can produce some degree of hypoferremia even in adrenalectomized dogs. Whether or not this is by direct stimulation of the reticulo-endothelial system or through some intermediary channel other than the pituitary-adrenal axis, are possibilities which deserve consideration and are now under study in this laboratory.

The studies reported here in dogs have been repeated and extended in rats (19). In general, the results in rats have confirmed the dog studies.

It must be emphasized that the data presented in this paper concern the mechanism by which acute hypoferremia occurs in the dog. It is possible that the same mechanism is operative in the production of the chronic hypoferremia which accompanies chronic infections in man although no direct evidence in support of this has been presented in this paper. Indeed, to date we have not observed hypoferremia in man following the administration of ACTH. These studies are now being extended.

\section{SUMMARY}

1. It has been shown that a variety of agents other than bacterial and sterile turpentine abscesses produce acute hypoferremia in dogs. These include histamine, epinephrine, fracture, anaphylactic shock and mild stress.

2. The injection of adrenocortical extract and adrenocorticotrophic hormone produced a similar hypoferremia.

3. Adrenalectomy abolished the hypoferremia produced by mild stress and by ACTH; the hypoferremia-producing effect of epinephrine was significantly reduced in the adrenalectomized dog but was not abolished.

4. Intravenously administered saccharated oxide of iron disappeared rapidly from the plasma of intact dogs given ACTH and more slowly from the plasma of adrenalectomized dogs. The ad- 
ministration of colloidal thorium dioxide also resulted in a decreased rate of disappearance of injected iron.

5. The intravenous injection of Dibenamine failed to block the hypoferremia-producing effect of epinephrine and itself produced a hyperferremia maximal in two hours and a hypoferremia which began in eight hours and was maximal at 24 hours.

6. When the various agents were employed, a correlation was observed between the degree of lymphopenia and eosinopenia produced and the degree of hypoferremia which developed.

\section{ACKNOWLEDGMENTS}

We are grateful for generous supplies of adrenocorticotrophic hormone (ACTH) to Dr. E. E. Hays, Armour and Company, Chicago, Illinois; saccharated oxide of iron (Ferrivenin) and Dibenamine to Dr. E. B. McLean and Dr. H. R. Knoch of the Smith, Kline and French Laboratories, Philadelphia, Pa.; lipo-adrenal cortex and aqueous adrenal cortex extract to Dr. J. F. Norton, the Upjohn Company, Kalamazoo, Michigan; and desoxycorticosterone acetate (Percorten) to Dr. E. Oppenheimer, Ciba Pharmaceutical Products, Summit, New Jersey.

We are indebted to Miss Betty Tatting, to Miss Jean Robinson, Mr. George Trappett and Mr. Ocie Hadley for technical assistance.

\section{REFERENCES}

1. Cartwright, G. E., Lauritsen, M. A., Jones, P. J., Merrill, I. M., and Wintrobe, M. M., The anemia of infection. I. Hypoferremia, hypercupremia, and alterations in porphyrin metabolism in patients. J. Clin. Invest., 1946, 25, 65.

2. Cartwright, G. E., Lauritsen, M. A., Humphreys, S., Jones, P. J., Merrill, I. M., and Wintrobe, M .M., The anemia of infection. II. The experimental production of hypoferremia and anemia in dogs. J. Clin. Invest., 1946, 25, 81.

3. Cartwright, G. E., Gubler, C. J., and Wintrobe, M. M.. The anemia of infection. XII. The effect of turpentine and colloidal thorium dioxide on the plasma iron and plasma copper of dogs. J. Biol. Chem., 1950, 184, 579.

4. Wintrobe, M. M., Greenberg, G. R., Humphreys, S. R., Ashenbrucker, H., Worth, W., and Kramer, R., The anemia of infection. III. The uptake of radioactive iron in iron-deficient and in pyridoxinedeficient pigs before and after acute inflammation. J. Clin. Invest., 1947, 26, 103.

5. Greenberg, G. R., Ashenbrucker, H., Lauritsen, M., and Wintrobe, M. M., The anemia of infection. IV. The lack of relationship between the diversion of iron from the plasma and the origin of the anemia. J. Clin. Invest., 1947, 26, 114.
6. Kuhns, W. J., Gubler, C. J., Cartwright, G. E., and Wintrobe, M. M., The anemia of infection. XIV. Response to massive doses of intravenously administered saccharated oxide of iron. J. Clin. Invest., 1950, 29, 1505.

7. Greenberg, G. R., Ashenbrucker, H., Lauritsen, M., Worth, W., Humphreys, S. R., and Wintrobe, M. M., The anemia of infection. V. Fate of injected radioactive iron in the presence of inflammation. J. Clin. Invest., 1947, 26, 121.

8. Hamilton, L. D., Gubler, C. J., Cartwright, G. E., and Wintrobe, M. M., The diurnal variation in the plasma iron level of man. Proc. Soc. Exper. Biol. \& Med., 1950, 75, 65.

9. Barkan, G., and Walker, B. S., Determination of serum iron and pseudohemoglobin iron with O-phenanthroline. J. Biol. Chem., 1940, 135, 37.

10. Dougherty, T. F., and White, A., An evaluation of alterations produced in lymphoid tissue by pituitaryadrenal cortical secretion. J. Lab. \& Clin. Med., 1947, 32, 584.

11. Recant, L., Hume, D. M., Forsham, P. H., and Thorn, G. W., Studies on the effect of epinephrine on the pituitary-adrenocortical system. J. Clin. Endocrinol., 1950, 10, 187.

12. Hills, A. G., Forsham, P. H., and Finch, C. A., Changes in circulating leukocytes induced by the administration of pituitary adrenocorticotrophic hormone (ACTH) in man. Blood, 1948, 3, 755.

13. Henneman, P. H., Wexler, H., and Westenhaver, M. M., A comparison of eosin-acetone and phloxinepropylene glycol diluents in eosinophil counts. J. Lab. \& Clin. Med., 1949, 34, 1017.

14. Gardner, M. V., The Blood Picture of Normal Laboratory Animals. A Review of the Literature, 1936-1946. Biochemical Research Foundation, Newark, Delaware, 1947.

15. Tepperman, J., and Bogardus, J. S., Attempts at pharmacologic blockade of the secretion of adrenocorticotrophin. Endocrinology, 1948, 43, 448.

16. Gross, H., Sandberg, M., and Holly, O. M., Changes in copper and in iron retention in chronic diseases accompanied by secondary anemia. II. Changes in liver, spleen and stomach. Am. J. M. Sc., 1942, 204, 201.

17. Jaffé, R. H., The Reticulo-Endothelial System, in Handbook of Hematology, edited by Downey, $\mathrm{H}$. Paul B. Hoeber, New York City, 1938, Vol. II, p. 977.

18. Gordon, A. S., and Katsh, G. F., The relation of the adrenal cortex to the structure and phagocytic activity of the macrophagic system. Ann. New York Acad. Sc., 1949, 52, 1.

19. Hamilton, L. D., Gubler, C. J., Ashenbrucker, H., Cartwright, G. E., and Wintrobe, M. M., The anemia of infection. XV. Studies on the relationship of the adrenal cortex to the experimental production of hypoferremia in rats. Endocrinology, in press. 